\title{
Inductively Coupled Plasma Mass Spectrometry with an Enlarged Sampling Orifice and Offset Ion Lens. I. Ion Trajectories and Detector Performance
}

\author{
Ke Hu*, P. Scott Clemons, and R. S. Houk \\ Ames Laboratory-U.S. Department of Energy, Department of Chemistry, Iowa State University, Ames, lowa, \\ USA
}

\begin{abstract}
A new inductively coupled plasma mass spectrometer (ICP-MS) with four stages of differential pumping is described. The relatively large sampling orifice $(1.31-\mathrm{mm}$ dia.) improves signals for metal ions and resists plugging from deposited solids. A new ion lens is described that deflects ions off center and then back on center into the differential pumping orifice; there is no photon stop in the center of the beam. Calculations of ion trajectories using SIMION show that only those ions that leave the skimmer on center are transmitted, whereas most other lenses used in ICP-MS transmit only ions that leave the skimmer off axis. The performance of a Channeltron electron multiplier is compared to that of a Daly detector. Both detectors yield similar sensitivities of $\sim 10^{6}{\text { counts } s^{-1}}_{\text {per ppm and detection limits of } \sim 1}$ pptr. The background with a Channeltron electron multiplier is only 0.4 counts $\mathrm{s}^{-1}$ and is only slightly higher than the dark current count rate. Presumably the offset ion lens used in the present work efficiently screens the detector from photons emitted by the plasma. The background with the Daly detector is 4 counts $s^{-1}$, which represents a substantial improvement over the background obtained in previous use of the Daly detector with ICP-MS. ( $\mathrm{J}$ Am Soc Mass Spectrom 1993, 4, 16-27)
\end{abstract}

I nductively coupled plasma mass spectrometry (ICP-MS) has become an important technique for -elemental and isotopic analysis because of its high selectivity and excellent detection limits (1-50 pptr). Despite these features, the analytical performance of ICP-MS is nevertheless limited by problems like spectral overlap from polyatomic ions (e.g., $\mathrm{ArO}^{+}$and $\mathrm{ArCl}^{+}$), noise in the background, matrix effects, and clogging of the sampling orifice by deposited solids [1]. This paper and its companion [2] address instrumental studies designed to improve the performance of ICP-MS in these areas.

The ICP is an intense source of both ions and photons and emits some strong lines in the vacuum ultraviolet [3]. These photons are usually screened from the detector by blocking the line of sight through the device with an optical baffle incorporated into the ion lens [4-6]. Alternatively, the multiplier or mass analyzer can be offset far from the axis, with appropriate optics to deflect the ions [7-10]. Despite these measures to screen the detector from the plasma, most

\footnotetext{
* Present address: Thermo Jarrell-Ash Corp. 8E Forge Parkway, Franklin, MA 02038-3148.

Address reprint requests to R. S. Houk, Ames Laboratory-U.S. Department of Energy, Department of Chemistry. Iowa State University, Ames, IA 50011.
}

quadrupole-based ICP-MS instruments have a substantial continuum background (i.e., background at a mass-to-charge ratio devoid of ions) of 5 to 20 counts $\mathrm{s}^{-1}$. The cause(s) of this remaining background are not known precisely. Perhaps a few ions pass straight down the axis of the quadrupole and are not filtered regardless of the mass-to-charge setting. Alternatively, some photons might be created inside the quadrupole when unstable ions strike the rods with high kinetic energies. These photons may then reach the defector. Further attenuation of the background is obviously desirable regardless of its cause.

The diameter of the sampling orifice (usually $\sim 1$ $\mathrm{mm}$ ) affects signal characteristics strongly in ICP-MS. For example, Vaughan and Horlick [11] reported that the count rate of monatomic analyte ions $\left(\mathrm{M}^{+}\right)$increased by a factor of ten and the ratio of oxide ions to analyte ions $\left(\mathrm{MO}^{+} / \mathrm{M}^{+}\right)$decreased greatly when the diameter of the sampler was altered from 0.51 to 0.94 $\mathrm{mm}$. Increasing the size of the sampling orifice would also be expected to improve the tolerance of the sampler to clogging from solids deposited from the sample [12].

In this paper the performance of a new ion lens is described. The ions from the skimmer are deflected and then brought back to the central axis. The lens 
electrodes themselves block photons effectively from the detector. A large sampling orifice (1.31-mm dia.) improves ion signals and resists plugging. These experiments are performed on an ICP-MS device with four differentially pumped chambers, as opposed to the usual three, to handle the additional gas load from the larger sampling aperture. With the four-stage chamber, the pressure in the detector chamber is low enough for proper use of the Daly detector [13, 14]. The relative merits of this detection method are compared with those obtained with a Channeltron electron multiplier. The companion paper [2] describes spectral overlap and matrix interferences with the new ICP-MS instrument, both of which are substantially less severe than those seen with most other ICP-MS devices.

\section{Experimental}

Vacuum system. The sampling interface and mass spectrometry part of the apparatus are depicted in Figure 1. Instrumental components and operating conditions are identified in Table 1 . The basic features of the ultrasonic nebulizer [16, 17], ICP, and sampling interface $[18,19]$ have been described previously. The expansion chamber was pumped by a rotary pump (Trivac model D30A, Leybold Vacuum Products (Export, PA); pumping speed, $10 \mathrm{~L} \mathrm{~s}^{-1}$ ). The ion lens chamber was pumped by a diffusion pump equipped with a liquid nitrogen cooled baffle (model VHS-6, Varian Associates; net pumping speed, $1600 \mathrm{~L} \mathrm{~s}^{-1}$ ). The quadrupole and detector chambers were pumped by turbomolecular pumps (model TMP 360V, Leybold Vacuum Products; pumping speed, $400 \mathrm{~L} \mathrm{~s}^{-1}$ ). Unlike most ICP-MS devices, there was $\mathrm{nn}$ isolation valve behind the skimmer. Instead, slide valves to the rotary pump and the diffusion pump were closed and the turbomolecular pumps were turned off to vent the chamber for maintenance. A small Viton disk was pressed gently onto the outside of the sampler to seal off the system for evacuation after service.

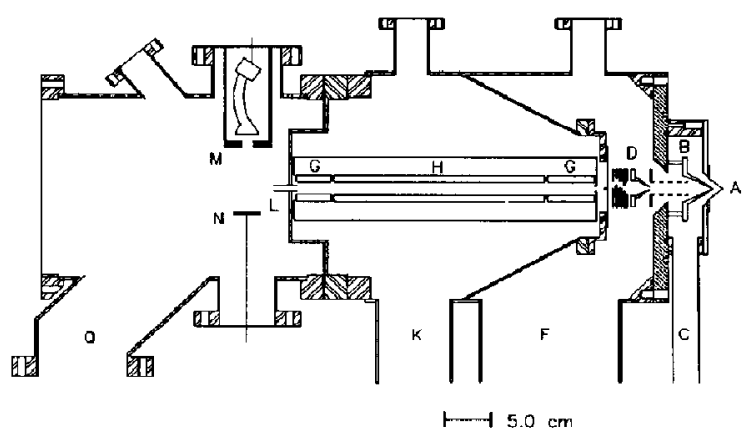

Figure 1. Schematic of mass spectrometer (ICP not shown): (A) sampler; (B) skimmer; (C) port to rotary pump; (D) ion lens (see Figure 2); (F) port to diffusion pump (1600 L s $\mathrm{s}^{-1}$ ); (G) rf-only quadrupoles; $(\mathrm{H})$ quadrupole mass analyzer; $(\mathrm{K})(\mathrm{Q})$ ports to turbomolecular pumps ( $400 \mathrm{~L} \mathrm{~s}^{-1}$ ); (L) exit ion lens; (M) aperture to electron multiplier; (N) deflection plate.
Ion sampling interface. A scale drawing of the ICP-MS sampling interface is shown in Figure 1. The sampling cone A was made from nickel. The orifice diameter was enlarged to $1.31 \mathrm{~mm}$ from the original $0.79 \mathrm{~mm}$. The diameter of the skimmer orifice was also $1.31 \mathrm{~mm}$. The angles and other dimensions of the sampler and skimmer were described elsewhere [18]. The distance between the sampler orifice and skimmer orifice was varied by changing the thickness of the copper spacer between the skimmer base and the vacuum chamber until the best signals were obtained for $\mathrm{Co}^{+}$and $\mathrm{Ho}^{+}$. The skimmer position was reoptimized when each different sampling orifice size was drilled. Eventually, the sampler-skimmer spacing was set to $11 \mathrm{~mm}$ with the 1.31-mm sampling orifice and skimmer orifice. At this position, the skimmer tip was $2 / 3$ of the way from the sampling orifice to the onset of the Mach disk, which also yielded optimum sensitivity for Douglas and French [19]. The copper flange that mounted the skimmer to the vacuum chamber (Figure 1) was water cooled.

Ion lens. The new ion lens is shown in Figure 2. Ions passing the skimmer orifice $A$ entered the first stainless steel cylinder 1. Numerous holes were drilled in the side wall of the cylinder so that neutral atoms could be evacuated. The second element of the lens (2) was a copper cone with a circular orifice of $2.5-\mathrm{mm}$ diameter. After the copper cone, ions passed a series of circular apertures ( $6.35 \mathrm{~mm}$ diameter) in stainless steel plates (3-6 in Figure 2) that were $1.65 \mathrm{~mm}$ thick. Lens 3 was made thicker by putting three plates together. The spacing between each lens was $2.5 \mathrm{~mm}$. Thinner spacers between lenses were tried but yielded poorer ion signals. Ions passing lens 6 were bent back farther to center to pass the differential pumping orifice 7 , which was a tube $2.50 \mathrm{~mm}$ dia. $\times 6.4 \mathrm{~mm}$ long. After the differential pumping orifice 7, the ions passed through the quadrupole entrance 8 , which included the dielectric ELFS $^{\circledR}$ tube supplied by Extrel (Pittsburgh, PA). The ICP, sampler, skimmer, and quadrupole were kept on the same center line.

Separate voltages $\left(V_{1}, V_{2}, V_{3}, V_{4}, V_{3}, V_{6}, V_{7}\right)$ were applied to the ion lens elements. For maximum transmission of ${ }^{153} \mathrm{Eu}^{+}$(a typical ion in the middle of the mass range for atomic ions), the optimum voltages were $V_{1},+3 \mathrm{~V} ; V_{2},-250 \mathrm{~V} ; V_{3},+1 \mathrm{~V} ; V_{4},+18 \mathrm{~V} ; V_{5}$, $-250 \mathrm{~V} ; V_{6},+18 \mathrm{~V} ; V_{7},-180 \mathrm{~V} ;$ and $V_{8},-20 \mathrm{~V}$. It is interesting that applying voltages of oppositc polarity to adjacent lenses tended to yield maximum ion transmission. This lens may operate somewhat like the periodic ion lens used to focus high-density ion beams [20].

Radiofrequency-only quadrupole and exit lens. As shown in Figure 1, short radiofrequency (rf)-only quadrupoles were mounted both before and after the mass analyzer. Both rf-only quadrupoles had the same rod diameter $(1.60 \mathrm{~cm})$ as the mass analyzer quadrupole and were 
Table 1. Instrumental facilities

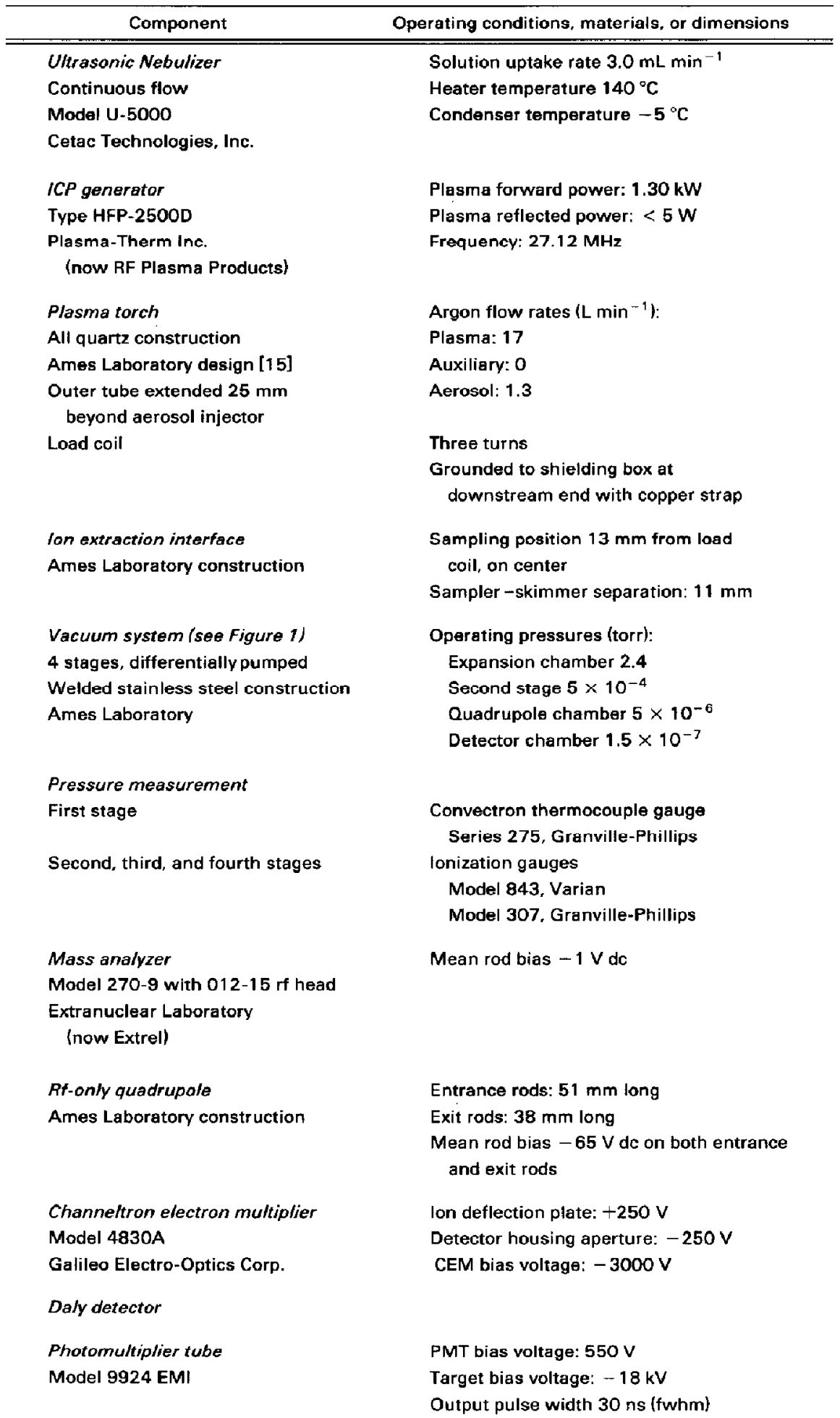


Table 1-Continued

\begin{tabular}{ll}
\hline \multicolumn{1}{c}{ Component } & Operating conditions, materials, or dimensions \\
\hline \hline $\begin{array}{l}\text { Counting electronics } \\
\text { Model } 1763 \text { preamplifier }\end{array}$ & Maximum count rate capability $20 \mathrm{MHz}$ \\
Model 1762 amplifier -discriminator & Pulse width $40 \mathrm{~ns}$ \\
Photochemical Research Associates & TL output \\
$\begin{array}{l}\text { Multichannel Analyzer } \\
\text { Model } 66 \text { with } 20 \mathrm{MHz} \text { dual-input } \\
\text { multichannel scanning option }\end{array}$ & Dwell time: $50 \mu \mathrm{s} /$ channel \\
Nuclear Data, Inc. & 4096 channels $/ \mathrm{sweep}$ \\
\hline
\end{tabular}

separated from the analyzer by a gap of $1.25 \mathrm{~mm}$. A single rf power supply was used to drive the three quadrupoles. The two sets of rf-only quadrupole rods were connected in parallel to each other. High-voltage capacitors ( $50 \mathrm{pF}, 7.5 \mathrm{kV}$ max.) were connected between the rf-only rods and the mass analyzer rods to shield the dc component from the rf-only quadrupoles. The mean dc bias of the two rf-only quadrupoles was the same and could be adjusted differently from that of the mass analyzer.

Ions leaving the exit rf-only quadrupole then passed through a long, thin stainless steel tube $(2.5 \mathrm{~cm} \times 6$ $\mathrm{mm}$ inside dia.) called the exit lens. This lens is shown as $\mathrm{L}$ in Figure 1. The exit lens was sealed with an electrically insulating gasket and was maintained at $-50 \mathrm{~V}$. The exit lens also served as the differential pumping orifice between the quadrupole and detector chambers. Because of this conductance restriction and the separate pump used, the pressure in the detector chamber was quite low (1.5 $\times 10^{-7}$ torr $)$ during operation. This additional pumping stage helped compensate for the high gas load through the large sampler and skimmer.

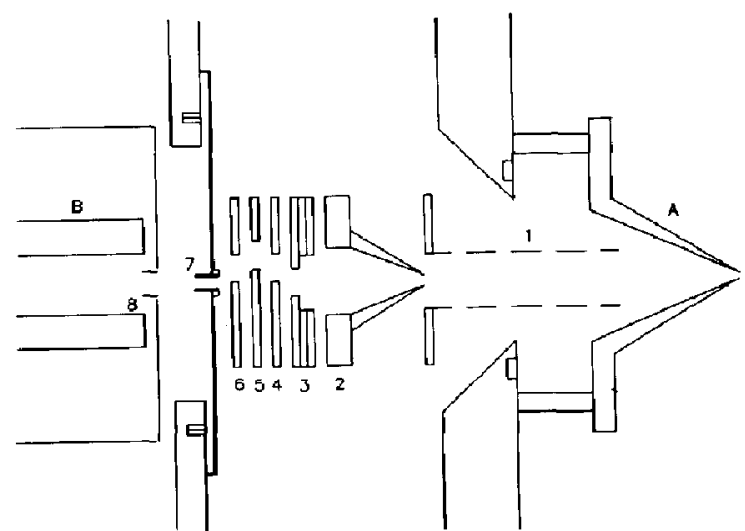

Figure 2. Schematic of ion lens system: (A) skimmer (grounded); (B) rf-only quadrupole at entrance to mass filter; (1) perforated cylinder, first element of ion lens; (2) copper cone, second element of ion lens; (3-6) stainless steel plates with circular apertures, third to sixth elements of ion lens; ( 7 ) differential pumping orifice; (8) entrance lens into rod housing.
Channeltron electron multiplier. The basic features of the Channeltron electron multiplier (Galileo ElectroOptics Corp., Sturbridge, MA) have been described elsewhere [21]. 'l'he detector arrangement is shown in Figure 1. The multiplier and ion deflector were offset above and below the center line of the sampler, skimmer, and quadrupoles. The Channeltron was shielded in a grounded, stainless steel case. A stainless steel plate with a circular aperture (1.25-cm dia.) was placed in front of the stainless steel case and was used to attract ions into the Channeltron. This plate was $5.0 \mathrm{~cm}$ from the center line through the quadrupole and was operated with an applied potential of $-250 \mathrm{~V}$. The deflecting plate (see Figure 1) was aligned with the mouth of the Channeltron, was placed $2.5 \mathrm{~cm}$ below the ion exit lens, and was operated at $+240 \mathrm{~V}$.

Daly detector. The basic features of the Daly detector and the procedures for preparing the aluminum target and scintillator for ICP-MS have been described [13, 14]. The detector assembly is shown in Figure 3. The target (M, Figure 3) was $2.5 \mathrm{~cm}$ above the center line through the quadrupole and the scintillator was $5.7 \mathrm{~cm}$ below it. The PMT assembly has also been described [5]. The rf leads to the mass filter did not pass through the detector chamber, so that if radiation from the quadrupole power supply did not interfere with the detector.

Data acquisition. Detection limits were measured as described in ref 14 . The detection limit is generally considered to be the solution concentration necessary to yield a net peak height equivalent to three times the standard deviation of the background. However, the background with the Channeltron detector was so low that the standard deviation for most elements was below 1 count $\mathrm{s}^{-1}$ and was difficult to measure directly. Therefore, the detection limit was estimated to be the solution concentration necessary to yield a net peak height equivalent to three times the estimated standard deviation, $B^{1 / 2}$, where $B$ was the background count rate. Calibration curves were determined in the multichannel scanning mode [ref $1, p .44]$ using the signal peak height. The dwell time was 50 


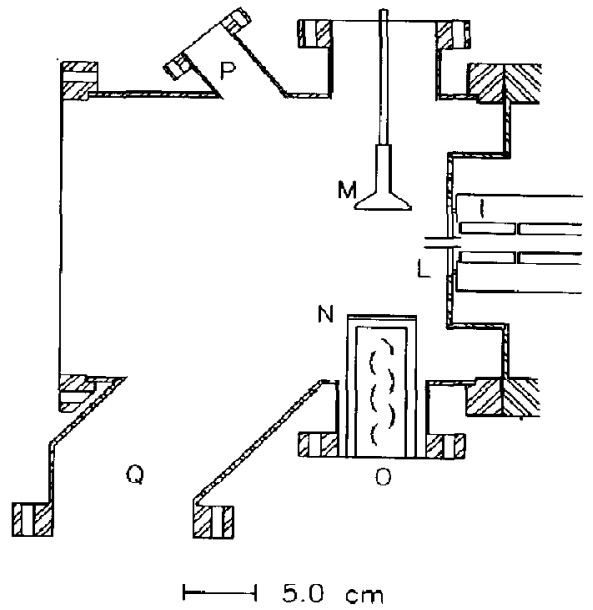

Figure 3. Schematic of Daly detector and detector chamber: (I) exit rf-only rods; (L) exit ion lens; (M) polished Al target; (N) scintillator with grounded metal film; (O) photomultiplier tube; (P) port to ion gauge; $(Q)$ port to turbo pump.

$\mu$ address $^{-1}$ for 4096 addresses over a mass window of 20 mass-to-charge ratio units wide. Fifty such sweeps were averaged. The mass analyzer was operated at unit mass resolution in the mass range measured.

Ion kinetic energies were measured by applying a positive stopping voltage as the mean $\mathrm{dc}$ bias to the quadrupole mass filter [22-24]. The stopping voltage necessary to attenuate the ion signal to $5 \%$ of the original signal level was measured and is referred to as "maximum ion energy" subsequently.

Ion trajectories. The trajectories through the ion lens were modeled with SIMION (version 4.0) [25] on an IBM personal computer. No corrections for spacecharge effects $[18,26,27]$ were used. Trajectories were calculated for initial ion kinetic energies of 4 to $11 \mathrm{eV}$ to account for the dependence of kinetic energy on mass-to-charge ratio [23]. The sloped surfaces of the skimmer and conical ion lens were approximated by small interconnected squares echeloned at $45^{\circ}$.

Solutions and standards. Standard solutions of $\mathrm{Co}, \mathrm{Cu}$, and Mo were $0.5 \mathrm{mg} \mathrm{L}^{-1}$ (ppm), $\mathrm{Zn}$ was $1.0 \mathrm{ppm}$, and $\mathrm{Y}, \mathrm{Rh}, \mathrm{Cs}, \mathrm{Ho}, \mathrm{Pb}$, and $\mathrm{U}$ were $0.2 \mathrm{ppm}$ and were prepared by diluting aliquots of commercial stock solutions (1000 ppm, Fisher Scientific, Fair Lawn, NJ) with distilled deionized water (18 M $\Omega$, Barnstead, Newton, MA).

\section{Results and Discussion}

\section{Diameter of Sampling Orifice}

These experiments were performed by drilling out the circular aperture in a single nickel cone progressively.
After each drilling, the separation between sampler and skimmer was adjusted empirically to maximize ion signal by substituting various spacers of different thickness behind the skimmer (Figure 2). This procedure was necessary because the background pressure increased and the supersonic jet shrank when the sampling orifice was enlarged $[18,19,28]$, and thus the optimum separation between sampler and skimmer changed as well.

The effect of sampling orifice diameter on ion signal for ${ }^{59} \mathrm{Co}^{+}$and ${ }^{209} \mathrm{Bi}^{+}$is shown in Figure 4. The signal increased by a factor of 8 when the sampling orifice was enlarged from $0.79-$ to $1.31-\mathrm{mm}$ dia. Each point in Figure 4 was measured at the sampler-skimmer separation that yielded maximum ion signal for each orifice diameter, as described in the previous paragraph. Vaughan and Horlick [11] observed a similar increase in ion signal when they increased the diameter of the sampling orifice from $0.51 \mathrm{~mm}$ to $0.94 \mathrm{~mm}$ on their Perkin Elmer Sciex (Thornhill, Ontario) instrument. The background pressure in the expansion chamber increased by a factor of 2.4 for the range of sampler diameters studied in the present work.

The voltages applied to the ion lenses were first selected to maximize signal for $\mathrm{Co}^{+}$and then reoptimized to provide maximum signal for $\mathrm{Bi}^{+}$for each sampler-skimmer separation. These optimum voltages changed by only a few volts for the range of orifice diameters shown in Figure 4. This variation was comparable to the day-to-day variation in "optimum" lens voltages seen subsequently when the sampling orifice was left at $1.31-\mathrm{mm}$ dia.

For three of the orifice diameters chosen, the pressure in the expansion chamber was also monitored as a

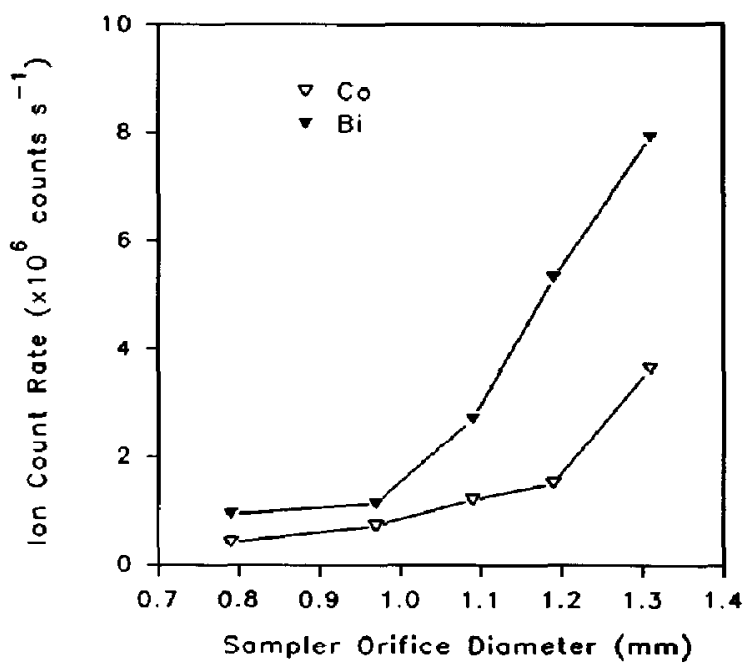

Figure 4. Ion count rates as a function of sampler orifice diameter. The separation between sampler and skimmer was optimized separately for each sampling orifice diameter as described in the text. 
function of time during continuous nebulization of a concentrated solution of yttrium (1000 ppm). This experiment was intended to evaluate the effect of sampling orifice size on tolerance to clogging. These results are shown in Figure 5. Each pressure measurement was normalized to the pressure obtained at time zero, that is, before the yttrium solution was introduced. With the $1.31-\mathrm{mm}$ dia. sampler, the pressure did not decrease noticeably over $100 \mathrm{~min}$. In contrast, the pressure decreases seen in Figure 5 for the smaller samplers indicated that they plugged readily. Note that these studies were conducted with a continuous flow ultrasonic nebulizer (Table 1), which transported material to the plasma at a rate at least 10 times greater than that obtained with a conventional pneumatic nebulizer $[16,17,29]$. Thus, the $0.1 \%$ Y solution used here was probably the equivalent of a $1 \%$ solution from a conventional nebulizer in terms of the rate of transport of material, which governed the deposition and clogging problems. At any rate, the $1.31-\mathrm{mm}$ dia. sampler used here proved quite resistant to clogging from deposited solids. This sampler was used for all the studies reported subsequently in this paper and its companion [2].

\section{Position of First Ion Lens}

Calculations by Olivares and Houk [18], Gillson et al. [26], and Tanner [27] indicate that efficient collection of ions leaving the skimmer is hampered by space charge effects, which disperse the ion beam on account of the very high current $(\sim 1 \mathrm{~mA})$ therein. We attempted to mitigate these effects and improve the collection efficiency by thrusting the first ion lens (1, Figure 2) as far as possible into the skimmer. A similar arrangement is employed in the high resolution ICP-MS device marketed by VG Elemental (Winsford, Cheshire, UK) [30]. As shown in Figure 6, a substantial increase in ion signal (by a factor of two to five) was seen when the separation between the skimmer tip and the entrance to the first lens was reduced to $2.4 \mathrm{~cm}$. At this position, the mouth of the first lens was only $\sim 5 \mathrm{~mm}$ from the nearest surface of the skimmer wall. Closer separations were tried, but the voltage output of the power supply for the first lens then became unstable, possibly because of an electrical discharge between the ion lens and the skimmer wall or a high current flow to the lens. Drilling holes through the wall of the first ion lens, as shown in Figure 2, also helped prevent this discharge problem. The $2.4-\mathrm{cm}$ separation was used for all subsequent work.

\section{Ion Trajectories and Kinetic Energies}

SIMION was used to model ion trajectories through the lens. First, the effect of ion kinetic energy on trajectory is shown in Figure 7. Ions that started on center with kinetic energies of 4 to $11 \mathrm{eV}$ were focused at a common point inside lens 5 and then deflected through the differential pumping orifice. After the differential pumping orifice, the ion paths diverged, so the efficiency with which ions of different energy were injected into the mass filter varicd somewhat.

This range of energies of $4-11 \mathrm{eV}$ corresponded closely to that observed for ions of different mass-tocharge ratio with this instrument (Iigure 8). The increase in ion energy with mass-to-charge ratio was caused by the acceleration of all ions to the same velucity in the supersonic jet, as described by Fulford

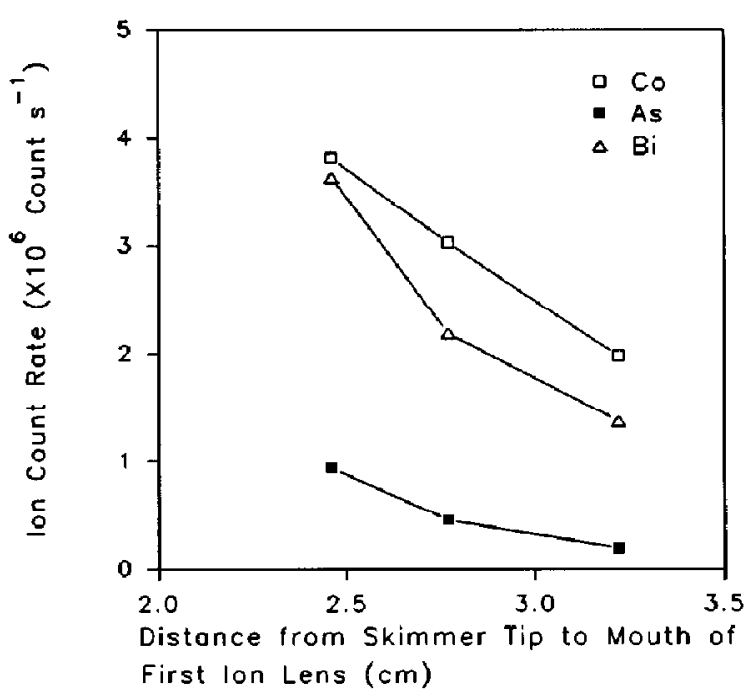

Figure 6. Ion count rates as a function of separation between skimmer tip and entrance to first ion lens.
Figure 5. Normalized interface pressure as a function of time for continuous nebulization of $1000 \mathrm{ppm} \mathrm{Y}$ at sampling orifice diameters.

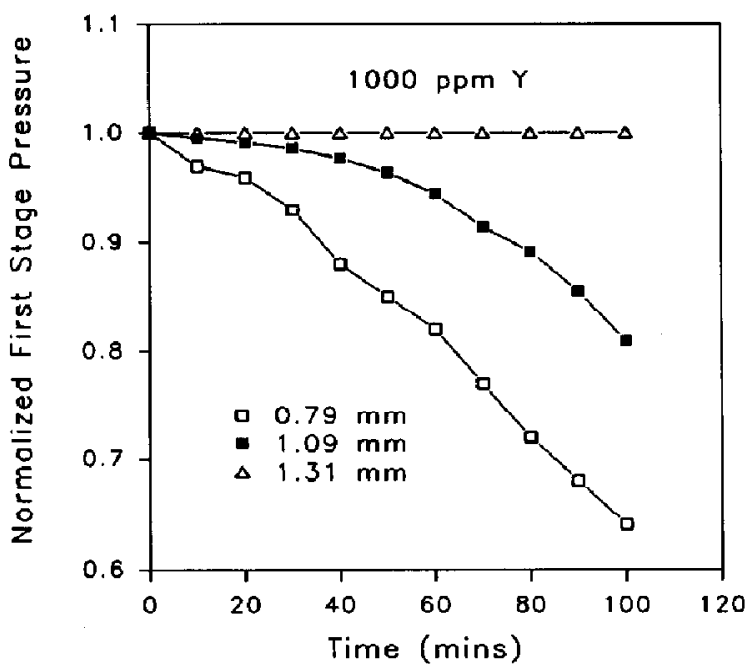




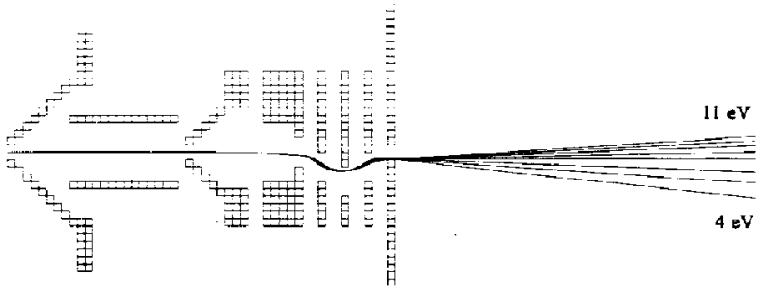

Figure 7. Trajectories for ions of varying kinetic energies. The skimmer is at the far left, and the differential pumping aperture is at the far right.

and Douglas [23]. The measured kinetic energy for $\mathrm{Li}^{+}$ was slightly above the line through the energies of the heavier ions, again in agreement with the results of Fulford and Douglas [23] and Tanner [27]. The latter author has attributed the slightly high value of kinetic energy for light ions such as $\mathrm{Li}^{+}$to space charge effects behind the skimmer.

The ion energies were measured on several different days and were reproducible within $\pm 0.5 \mathrm{eV}$, even though the lens voltages necessary to maximize the ion signal were slightly different from day to day. This high level of reproducibility in ion energy indicates that (1) the lens voltages did not affect the measured ion energies greatly, and (2) the sampling position and plasma operating conditions were also reproducible.

The trajectorics in Figure 9 illustrated the fate of ions that left the skimmer either at an angle or displaced radially relative to the central axis. SIMION indicated that such ions were focused in front of the conical lens, but these simulations ignored space charge effects, which were probably quite substantial here [26, 27]. Suppose for the moment that the ion current

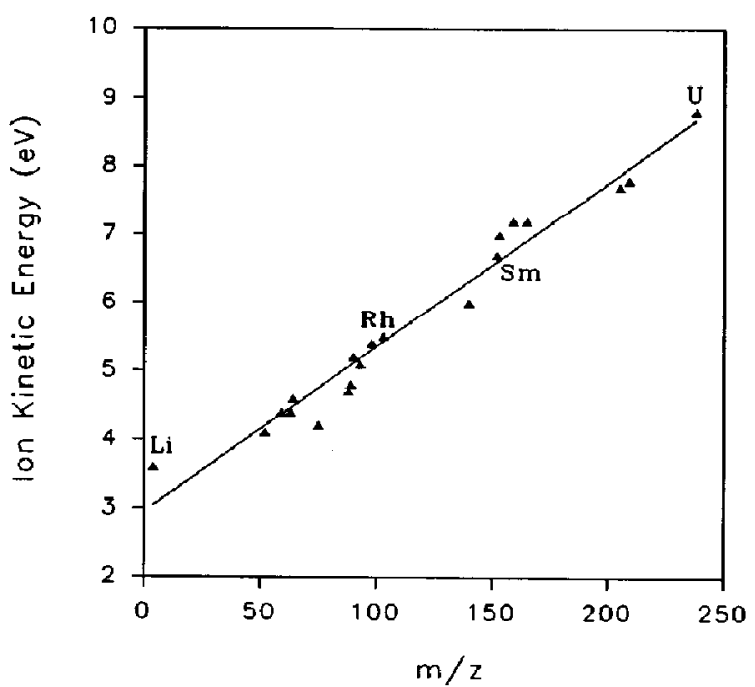

Figure 8. Maximum ion kinetic energies as a function of atomic mass.

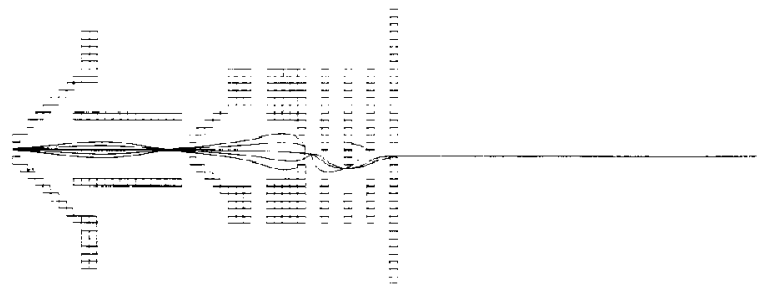

a

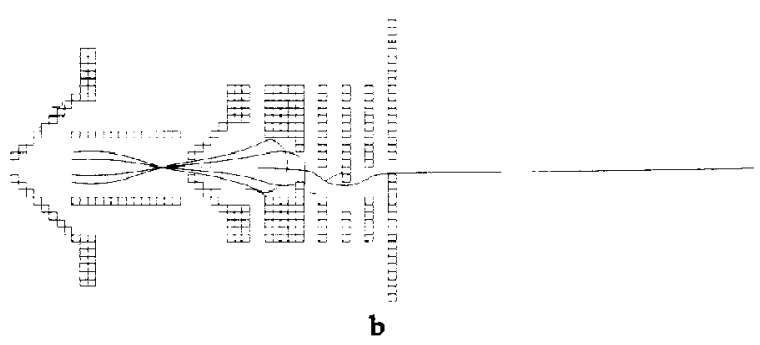

Figure 9. Ion trajectories for $6-\mathrm{eV}$ ions with different exit angles and radial positions leaving the skimmer. In (a), the exit angles are $-6^{\circ},-3^{\circ}, 0^{\circ},+3^{\circ},+6^{\circ}$. Only the ion that enters precisely on axis $\left(0^{\circ}\right)$ passes through the lens.

through the small conical lens (2.5-mm dia. at the tip) was low enough that space charge effects could be neglected aft of this lens. The SIMION trajectories in Figure 9 showed that off-axis ions entering the conical lens then struck one of the downstream lens electrodes and were not transmitted to the mass analyzer. Similar behavior was seen for off-axis ions of different kinetic energy than the 7-eV ions selected for Figure 9.

The spatial selectivity of this lens for on-axis ions contrasted strongly with the behavior of the lens in Perkin Elmer Sciex ICP-MS instruments. Because of the shadow stop and photon stop, this latter lens transmitted only ions that left the skimmer off axis [31]. Detailed simulations have not been reported for other lens assemblics, but it is likely that any lens with a central stop to block photons shows the same general behavior as the Perkin Fimer Sciex lens, at least to some extent.

There is another interesting difference between these ion optical simulations and those of Vaughan and IIorlick [31]. The voltages used in the SIMION calculations in the present work were close to (i.e., within a few volts) of the ones that yielded maximum ion transmission experimentally. In one previous simulation with the Perkin Elmer Sciex lens, the voltages required by SIMION for ion transmission differed substantially from those actually used on the instrument [31], although the general conclusions drawn as to the overall behavior of this lens were probably still reasonable. The ion lens simulation described recently by Tanner [27] does predict transmission of ions through the Perkin Elmer Sciex lens when the actual experimental voltages are used in the program. This proce- 
dure accounts for space charge effects. Application of this program to evaluate space charge effects in the ion lens described in the present work should prove interesting.

A final note of caution about the SIMION trajectories through this lens is necessary. First, the lens electrodes shown in Figures 7 and 9 were entered into SIMION in planar coordinates. They were actually circular apertures, but the present version of SIMION could not accept these electrode shapes except under conditions of cylindrical symmetry, which the present lens lacked. Second, these SIMION calculations were only two-dimensional, that is, they showed only trajectories in the plane of the page in Figures 7 and 9. Of course, the apertures in both the skimmer and the conical lens were circular, but trajectories of ions originating above or below the plane of the page could not be calculated by SIMION. Despite these limitations, SIMION did predict transmission of ions through the lens at the applied voltages that actually worked experimentally, so the authors felt that these simulations were at least qualitatively valid.

\section{Effect of Ion Lens Voltages on Mass Discrimination}

The variation of ion energy with mass-to-charge ratio (Figure 8) is one cause of mass discrimination in ICPMS. This problem complicates selection of a single set of lens voltages for multielement analysis. Similar effects were seen with the offset lens studied in the present work, as shown in Figures 10-12. For simplicity, these figures were referred to as "focusing curves." For each figure, only one lens voltage was varied at a time. The other lenses were kept at the voltages that yield maximum transmission for $\mathrm{Rh}^{+}$.

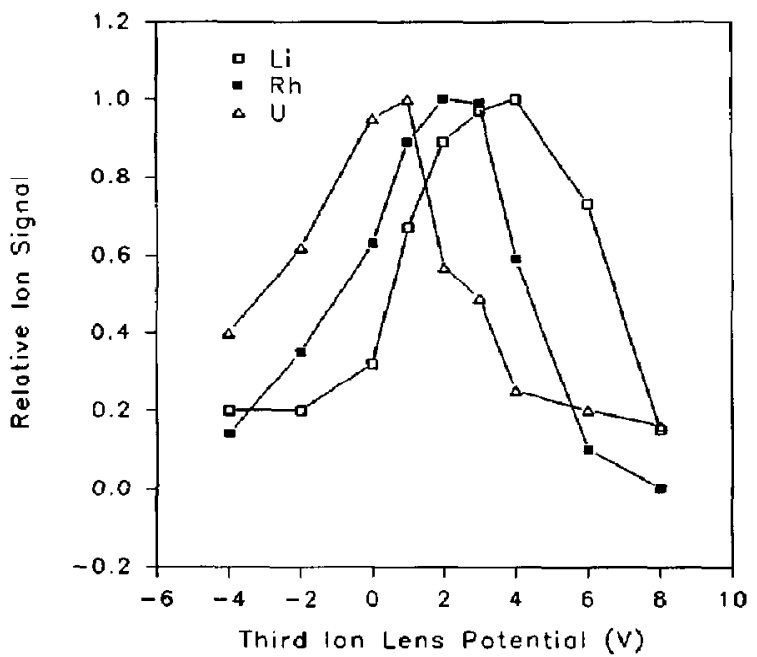

Figure 10. Normalized ion signals as a function of $V_{3}$ (see Figure 2) for $\mathrm{Li}^{+}, \mathrm{Rh}^{+}$, and $\mathrm{U}^{+}$.

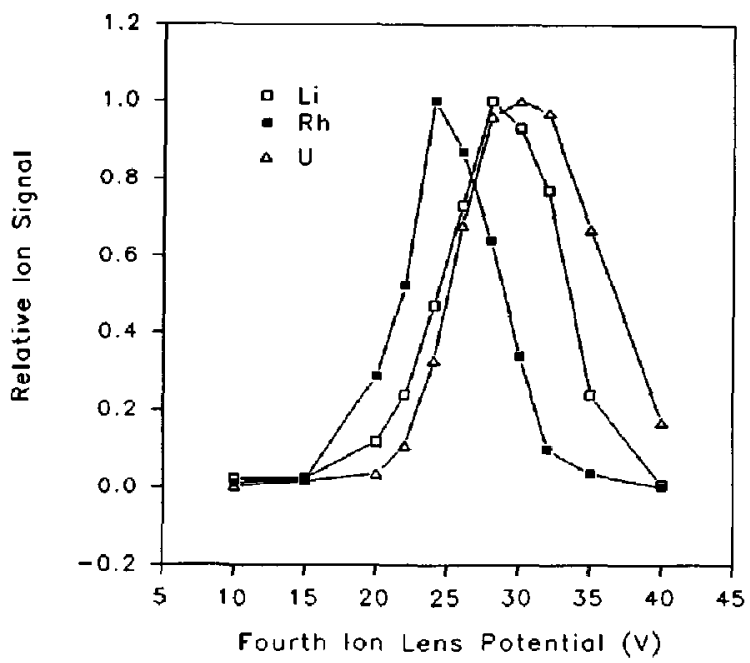

Figure 11. Normalized ion signals as a function of $V_{4}$ (see Figure 2) for $\mathrm{Li}^{+}, \mathrm{Rh}^{+}$, and $\mathrm{U}^{+}$.

Inspection of these focusing curves showed that their overall shapes and the order of voltages corresponding to maximum transmission for different elements varied for the three lenses. For example, for the third lens $\left(V_{3}\right.$, Figure 10$)$, the order of voltages that yielded maximum transmission was $\mathrm{U}^{+}<\mathrm{Rh}^{+}<\mathrm{Li}^{+}$. For the fourth lens $\left(V_{4}\right.$, Figure 11), the order was $\mathrm{Rh}^{+}<\mathrm{U}^{+} \leq \mathbf{L i}^{+}$, whereas for the sixth lens $\left(V_{6}\right.$, Figure 12) the order was $R h \leq U \leq \mathrm{Li}$. For the sixth lens (Figure 12), mass discrimination was minimal at a voltage of $+35 \mathrm{~V}$, that is, the signals for $\mathrm{Li}^{+}, \mathrm{Rh}^{+}$, and $\mathrm{U}^{+}$were all near their maxima at the same applied voltage. In contrast, some compromise in transmission

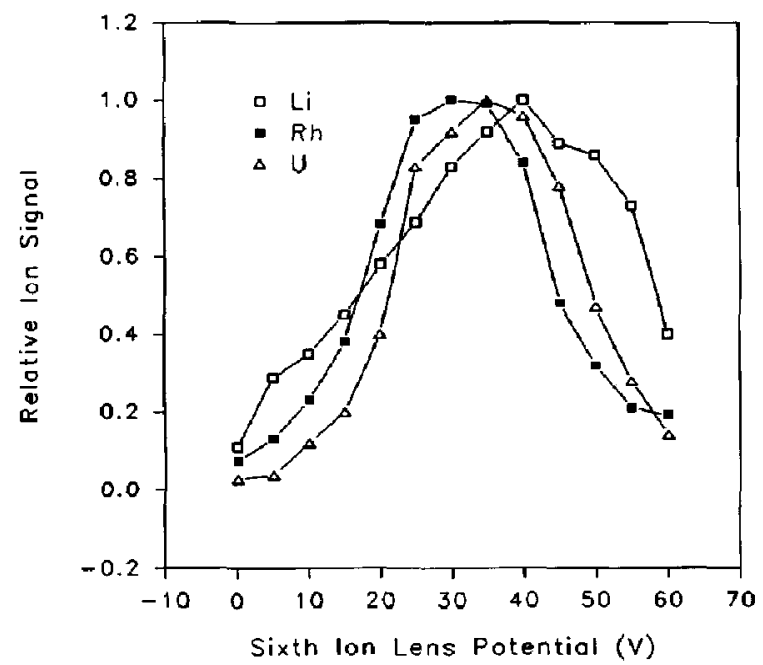

Figare 12. Normalized ion signals as a function of $V_{6}$ (see Figure 2) for $\mathrm{Li}^{+}, \mathrm{Rh}^{+}$and $\mathrm{U}^{+}$. 
was necessary when selecting the voltages applied to the third and fourth lenses. The focusing curve for $\mathrm{Li}^{+}$ was substantially broader than those for $\mathrm{Rh}^{\prime}$ and $\mathrm{U}^{\prime}$ for lenses 3 and 6 , whereas $U^{+}$had the broadest focusing curve for lens 4 . Focusing curves for the negative lenses $\left(V_{2}, V_{5}\right.$, and $V_{7}$ in Figure 2) were broad and featureless and were therefore not reported here.

\section{Background and Signal with Channeltron Electron Multiplier}

The detector arrangement shown in Figure 1 was used for these studies. Measurements of dark current (i.e., with the sampler closed) and background are listed in Table 2. These values were so low that long counting times (10 min) were required to obtain useful counting statistics. The dark current was $\sim 0.3$ counts $\mathbf{s}^{-1}$. Next, ions were sampled from the ICP with the mass analyzer set at a dc offset voltage of $-1 \mathrm{~V}$. In this condition, ions were injected into the mass analyzer, but the mass-to-charge ratio window was set to a high value in a part of the spectrum devoid of ions. The background increased only slightly to $\sim 0.4$ counts $\mathrm{s}^{-1}$. Finally, a high positive offset voltage $(+50 \mathrm{~V})$ was applied to the quadrupole rods so that ions could not enter the mass filter. The background did not change perceptibly, which indicated that the background was not caused by ions in or leaking out of the mass analyzer. Also, the background did not change noticeably as aerosol gas flow rate, plasma power, or ion lens voltages were changed. Our general experience with other lenses has been that adjusting the voltages to maximize ion transmission also induced an increase in background, but this problem was not seen with the offset lens described in the present paper.

These background values were much lower than those obtained on other quadrupole-based ICP-MS devices [1,4] and rivaled those obtained with ICP-MS instruments based on dnuble focusing mass spectrometers $[8,9]$. The background with this ICP-MS device with on-center, cylindrical ion lenses has been typically 1000 counts $s^{-1}$. With a photon stop, the background improved somewhat to $\sim 150$ counts $s^{-1}$. The offset ion lens and displaced detector arrangement

Table 2. Continuum background measurements

\begin{tabular}{|c|c|c|c|}
\hline \multirow[b]{2}{*}{$\begin{array}{l}\text { Sampler } \\
\text { status }\end{array}$} & \multirow[b]{2}{*}{$\begin{array}{c}\text { DC bias } \\
\text { on mass filter (V) }\end{array}$} & \multicolumn{2}{|c|}{$\begin{array}{l}\text { Integrated continuum } \\
\text { background } \\
\left.\text { (counts } s^{-1}\right)^{\text {a }}\end{array}$} \\
\hline & & $\begin{array}{c}\text { Channeltron } \\
\text { detector }\end{array}$ & $\begin{array}{c}\text { Daly } \\
\text { detector }\end{array}$ \\
\hline Closed & -1 & 0.3 & 3 \\
\hline Open to ICP & -1 & 0.4 & 4 \\
\hline Open to ICP & $+\mathbf{5 0}$ & 0.4 & 4 \\
\hline
\end{tabular}

${ }^{\theta}$ Counting time $\sim 10 \mathrm{~min}$ while scanning over $m / 2166$ to 200 . Deionized distilled water was nebulized. described here provided much lower backgrounds than we have obtained on any of our "home-made" devices with any of a variety of photon stops or detector geometries [5, 18, 32, 33].

The mass spectrum of $\mathrm{Ho}^{+}$, a monoisotopic rare earth element, is shown in Figure 13. For this figure, the ion lens voltages were adjusted to maximize transmission specifically for $\mathrm{Ho}^{+}$. The sensitivity (i.e., the count rate per unit concentration) was $\sim 10^{4}$ counts $\mathrm{s}^{-1}$ per $\mathrm{ppb}$ Ho, which would be equivalent to $\sim 10^{7}$ counts $\mathrm{s}^{-1}$ per $\mathrm{ppm}$, if the linear dynamic range extended to such high count rates. The sensitivity observed for $\mathrm{Ho}^{+}$compared well with that obtained for most other quadrupole-based ICP-MS devices [1], although two mitigating factors must be kept in mind: (1) a highly efficient ultrasonic nebulizer was used in the present work, and (2) the kinetic energy of $\mathrm{Ho}^{+}$ $(\sim 7 \mathrm{eV})$ is right in the best range for transmission through this lens, as indicated by the trajectory plots in Figure 7. The peak shapes were also much better than seen previously with this instrument, perhaps because of the RF-only rods on the entrance. Background counts were not shown in Figure 13 because none were seen in the time required $(\sim 1 \mathrm{~min})$ to measure this spectrum.

The sensitivities and detection limits obtained with the Channeltron detector are listed in Table 3. These data were obtained with two separate schemes for adjusting the voltages applicd to the lenses. The values labeled "single element conditions" were measured with the lens voltages adjusted separately to maximize signal for each group of elements of similar mass-tocharge ratio. For example, ${ }^{59} \mathrm{Co}^{+},{ }^{63} \mathrm{Cu}^{+}$, and ${ }^{64} \mathrm{Zn}^{+}$ were measured with the same lens settings, which differed from those used for ${ }^{98} \mathrm{Mo}^{+}$and ${ }^{103} \mathrm{Rh}^{+}$, or for ${ }^{208} \mathrm{~Pb}^{+}$and ${ }^{238} \mathrm{U}^{+}$. Alternatively, the values listed under "multielement conditions" were measured with the lens voltages adjusted for best transmission of

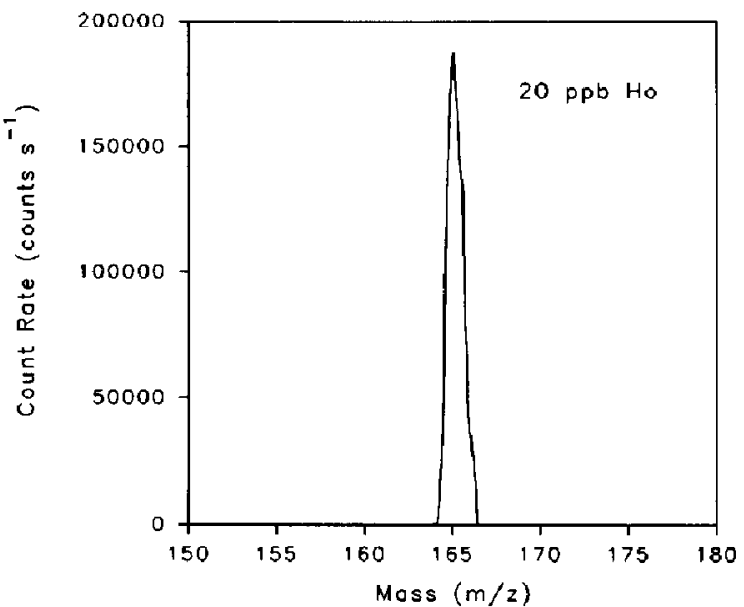

Figure 13. Mass spectrum of $\mathrm{Ho}$ at $20 \mathrm{ppb}$ with Channeltron detector. 
Table 3. Sensitivity and detection limits determined by Channeltron electron multiplier

\begin{tabular}{lrrr}
\hline & $\begin{array}{c}\text { Sensitivity* } \\
\text { Element (counts s }\end{array}{ }^{-1} / \mathrm{mg} \mathrm{L}^{-1}$ ) & $\begin{array}{c}\text { Sensitivity** } \\
\text { counts s }\end{array}{ }^{-1} / \mathrm{mg} \mathrm{L}^{-1}$ ) & $\begin{array}{c}\text { Detection } \\
\text { limits* } \\
\text { (ng L }{ }^{-1} \text { ) }\end{array}$ \\
\hline \hline${ }^{7} \mathrm{Li}$ & - & 190,000 & - \\
${ }^{69} \mathrm{Co}$ & $1,380,000$ & $1,170,000$ & 1 \\
${ }^{63} \mathrm{Cu}$ & $1,130,000$ & 858,000 & 1 \\
${ }^{64} \mathrm{Zn}$ & 390,000 & 302,000 & 5 \\
${ }^{89} \mathrm{Y}$ & $2,100,000$ & $1,770,000$ & 0.9 \\
${ }^{98} \mathrm{Mo}$ & 495,000 & 409,000 & 4 \\
${ }^{103} \mathrm{Rh}$ & $2,780,000$ & $2,540,000$ & 0.7 \\
${ }^{133} \mathrm{Cs}$ & $4,070,000$ & $4,070,000$ & 0.5 \\
${ }^{165} \mathrm{Ho}$ & $6,440,000$ & $2,770,000$ & 0.3 \\
${ }^{208} \mathrm{~Pb}$ & $2,500,000$ & $1,580,000$ & 0.8 \\
${ }^{238} \mathrm{U}$ & $2,150,000$ & 736,000 & 0.9 \\
\hline
\end{tabular}

* Single element conditions: ion lens voltages adjusted to maximize ion signal separately for each group of elements.

t* Muttielement conditions: ion lens voltages adjusted to maximize ion signal for $\mathrm{Cs}^{+}$only.

${ }^{133} \mathrm{Cs}^{+}$only. Comparison of the sersitivities in Table 3 showed that the multielement conditions involved little sacrifice in sensitivity compared to that obtained under single element conditions for the elements of moderate atomic weight such as $\mathrm{Co}$ and $\mathrm{Cu}$. However, signals for heavier elements such as $U$ were reduced by a factor of about two under multielement conditions.

In either case, detection limits were generally in the range $0.3-5 \mathrm{ng} \mathrm{L} \mathrm{L}^{-1}$ (pptr). These elements represented favorable cases in that all but $Z \mathbf{n}$ were quite efficiently ionized in the ICP [1]. These values were comparable to those obtained with most quadrupole-based instruments, which normally used the standard, less-efficient pneumatic nebulizers [1]. Apparently the somewhat lower sensitivity (accounting for differences in nebulization) seen with the present instrument was compensated by the lower background. It is interesting that both quadrupole ICP-MS instruments with substantially better sensitivity (i.e., the Yokogawa PMS 2000, Tokyo, Japan, and the TS Sola, Warrington, Cheshire, UK) also use offset ion lenses $[10,34$, and $p$. 34 of ref 1], but of different geometries than the one described in this paper. With these other offset ion lenses, the ions are diverted and then sent directly into an off-axis mass analyzer. Because the ions are not deflected back to the central axis (as in our lens, Figure 7), they are probably injected into the mass analyzer more efficiently with these other offset ion lenses. Thus, the sensitivity $\left(\sim 10^{8}\right.$ ions $\mathrm{s}^{-1}$ per ppm) achievable can be quite high with these devices.

A single sensitivity value is reported for ${ }^{7} \mathrm{Li}$ in Table 3. This value for ${ }^{7} \mathrm{Li}$ is substantially poorer than that seen for heavier, monoisotopic elements such as ${ }^{59} \mathrm{Co}$ or ${ }^{103} \mathrm{Rh}$. Presumably, ${ }^{7} \mathrm{Li}^{+}$is deflected more extensively by space charge effects than are heavier ions. Thus, fewer ${ }^{7} \mathrm{Li}^{+}$ions remain on the central axis.
Because the lens transmits on-center ions preferentially, the sensitivity for $\mathrm{Li}^{+}$is poorer than that for heavier elements, as is often the case with most quadrupole ICP-MS devices [1].

In a supplementary experiment, the turbo pump on the detector chamber (Figure 1) was shut off during sampling of ions from the ICP. The pressure in the detector chamber therefore rose gradually from $1.5 \times$ $10^{-7}$ to $3 \times 10^{-5}$ torr. The background and the ion signal observed were not affected by this increase in pressure in the detector chamber. Thus, the fourth pumping stage was not strictly necessary when the Channeltron was used. Three differentially pumped stages would have sufficed, despite the high gas load through the enlarged sampler and skimmer.

\section{Comparison with Daly Detector}

The Daly detector is shown in Figure 3. The variation of background with target voltage for this detector is shown in Figure 14. Background changed little until the target voltage was more negative than $\sim-18 \mathrm{kV}$, after which the background ruse sharply. This behavior indicated that the pressure in the target chamber $\left(1.5 \times 10^{-7}\right.$ torr) was still a little high for the Daly detector, although a much more negative target voltage was possible than the $-5 \mathrm{kV}$ used in our early experience with this detector at a pressure of $\sim 10^{-6}$ torr [14]. The target voltage was kept at $-18 \mathrm{kV}$ for subsequent studies.

As shown in Table 2, the dark current was $\sim 3$ counts $\mathrm{s}^{-1}$, and the background was $\sim 4$ counts $\mathrm{s}^{-1}$ with the Daly detector. These values were a bit higher than those seen with the Channeltron, and the background exceeded the dark current by about the same factor (1.3) as seen with the Channeltron.

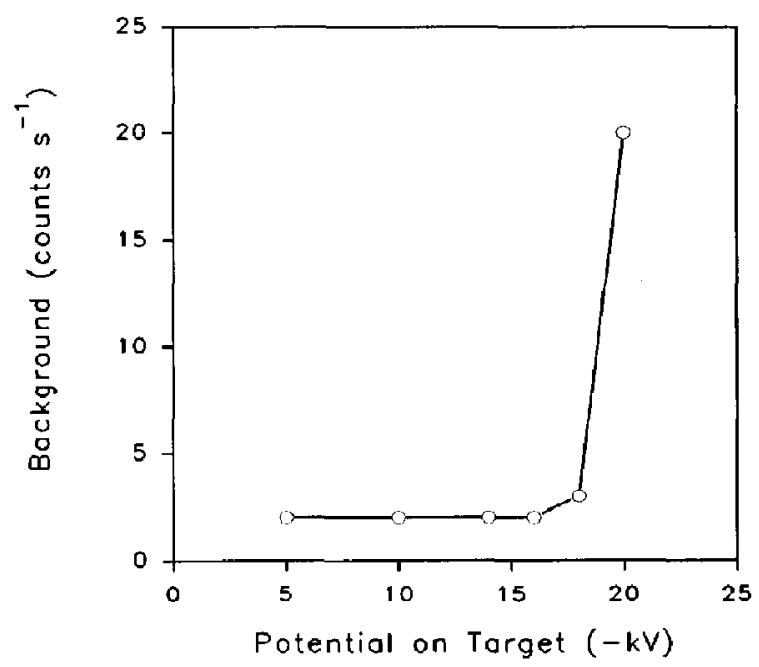

Figure 14. Background as a function of target potential with Daly detector. 
Sensitivities and detection limits obtained with the Daly detector under "multielement conditions" are given in Table 4. In general, sensitivity was similar (i.e., within a factor of two) for the two detectors. Detection limits were $0.6-20$ pptr. These values with the Daly detector were a bit poorer than those ob. tained with the Channeltron but were still quite respectable.

Finally, linearity, stability, and precision were evaluated with both detectors. As shown in Figure 15, the linear part of the calibration curve obtained with the Daly detector extended to somewhat higher count rate $\left(\sim 2 \times 10^{6}\right.$ counts $\left.\mathrm{s}^{-1}\right)$ than that obtained with the Channeltron, as seen previously [14]. A solution of 200 $\mathrm{Ppb}$ Rh was analyzed repetitively to evaluate precision and stability. The relative standard deviation of five successive measurements of ${ }^{103} \mathrm{Rh}^{+}$signal was $0.9 \%$ with the Daly detector and $3.0 \%$ with the Channeltron. The latter figure was representative of the short-term precision obtained in many experiments with the Channeltron detector on the instrument described here. Signal drift was measured over a longer period (2 hours). The signal observed from either detector drifted down over this period, as is common in ICP-MS. With the Daly detector, the average signal for ${ }^{103} \mathrm{Rh}^{+}$at 200 ppb drifted down by $3 \%$ in two hours. With the Channeltron, the signal drifted down by $10 \%$ in the same time period.

These measurements substantiate the following observations concerning stability and precision. First, the Daly detector yielded somewhat better stability and precision than the Channeltron, as seen previously [14]. Second, the difference in drift characteristics seen with the two detectors indicated that some of the drift in ICP-MS may be attributable to the Channeltrons that were commonly used. Perhaps there was a change in gain of a Channeltron over a time span of a few hours during ICP-MS operation. Finally, the offset ion lens was not particularly vulnerable to drift. The drift value reported here for the Channeltron ( $-10 \%$ over two hours) was only $-2 \times$ worse than the drift typi-

Table 4. Sensitivity and detection limits determined by Daly detector

\begin{tabular}{crc}
\hline Elements & $\begin{array}{c}\text { Sensitivity* } \\
\left.\text { (counts } \mathrm{s}^{-1} / \mathrm{mg} \mathrm{L}^{-1}\right)\end{array}$ & $\begin{array}{c}\text { Detection limits } \\
\left(\mathrm{ng} \mathrm{L}^{-1} \text { ) }\right.\end{array}$ \\
\hline \hline${ }^{59} \mathrm{Co}$ & $1,050,000$ & 6 \\
${ }^{63} \mathrm{Cu}$ & 467,000 & 10 \\
${ }^{64} \mathrm{Zn}$ & 235,000 & 20 \\
${ }^{89} \mathrm{Y}$ & $2,180,000$ & 3 \\
${ }^{98} \mathrm{Mo}$ & 520,000 & 10 \\
${ }^{103} \mathrm{Rh}$ & $5,440,000$ & 1 \\
${ }^{140} \mathrm{Ce}$ & $3,250,000$ & 2 \\
${ }^{165} \mathrm{Ho}$ & $9,550,000$ & 0.6 \\
${ }^{205} \mathrm{Tl}$ & $2,510,000$ & 2 \\
${ }^{208} \mathrm{~Pb}$ & $1,680,000$ & 4 \\
\hline
\end{tabular}

* Ion lens voltages adjusted to maximize ion signal for $\mathrm{Ho}^{+}$anly.

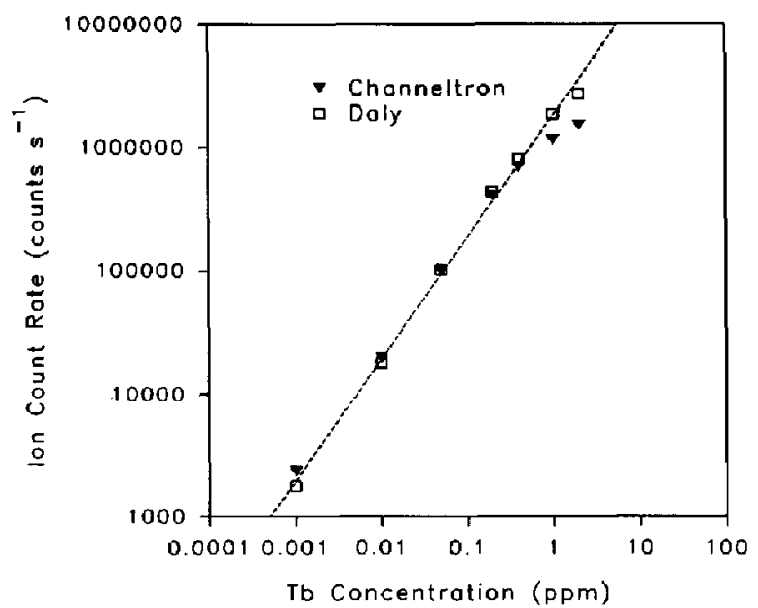

Figure 15. Calibration curves for ${ }^{159} \mathbf{T b}^{+}$with Daly detector ( $\square$ ) and Channeltron electron multiplier ( $\nabla$ ). The dashed line represents the extrapolation of the linear section. The gain of the photomultiplier tube was adjusted to bring the linear sections of the two curves into coincidence.

cally seen on modern commercial ICP-MS devices that use the same detectors. These latter instruments have the advantage of being engineered and tested exhaustively to minimize drift, whereas no special effort to minimize drift was expended in the present work. The $3 \%$ drift value obtained with the Daly detector is quite competitive with the drift performance of present ICPMS devices.

\section{Conclusions}

This paper describes experimental modifications to ICP-MS that provide improved tolerance to orifice plugging and lower continuum background and less background noise than that obtained with other quadrupole-based instruments. The ion lens used to reduce the background sacrifices analyte count rates somewhat. This lens differs markedly from most other lenses used in ICP-MS in that it transmits only those ions that leave the skimmer on center. Modest improvements in precision and linear dynamic range are possible with the Daly detector, if an additional stage of differential pumping is provided. Spectral interferences and matrix effects can also be reduced dramatically with this apparatus, as described in the accompanying paper [2].

\section{Acknowledgments}

The Ames Laboratory is operated by lowa State University for the U.S. Department of Energy under contract no. W-7405-Eng-82. This research was supported by the Office of Basic Energy Sciences, Division of Chemical Sciences. Financial support from the U.S. Department of Commerce through the Center for Advanced Techrology Development for construction for the ICP-MS device is also gratefully acknowledged. The ultrasonic nebulizer was provided by Cetac Technologies, Inc., Omaha, Nebraska. 


\section{References}

1. Jarvis, K. E.; Gray, A. L.; Houk, R. S. Handbook of Inductively Coupled Plasma Mass Spectrometry; Blackie: Glasgow, 1991.

2. Hu, K; Houk, R. S. J. Am. Soc. Mass Spectrom. 1993, 4.

3. LaFreniere, B. R.; Houk, R. S.; Fassel, V. A. Anal. Chem. 1987, $59,2276-2282$.

4. Kawaguchi, H.; Tanaka, T.; Mizuike, A. Spectrochim. Acta B $1988,43,955-962$.

5. Houk, R. S.; Fassel, V. A.; Flesch, G. D.; Svec, H. J; Gray, A. L.; Taylor, C. E. Anal. Chem. 1980, 52, 2283-2289.

6. Gray, A. L.; Date, A. R. Analyst 1983, 108, 1033-1050.

7. Ross, B. S.: Hieftje, G. M. Spectrochim. Acta B 1991, 46, 955-962.

8. Bradshaw, N.; Hall, E. F. H.; Sanderson, N. E. J. Anal. Atom. Spectrom. 1989, 4, 801-803.

9. Morita, M.; Ito, H.; Uehiro, T.; Otsuka, K. Anal. Sci. (Japan) $1989,5,609-610$.

10. Sakata, K. 78th FACSS Conf:; Anaheim, CA, October 1991; Paper No. 528.

11. Vaughan, M. A.; Horlick, G. Spectrochim. Acta B 1990, 45, 1289-1299.

12. Douglas, D. J.; Kerr, L. A. J. Anal. Atom. Spectrom. 1988, 3, 749-752.

13. Daly, N. R. Rev. Sci. Instrum. 1960, 37, 1385-1390.

14. Huang, L. Q.; Jiang, S. -J.; Houk, R. S. Anal. Chem. 1987, 59, 2316-2320.

15. Scott, R. H.; Fassel, V. A.; Kniseley, R. N.; Nixon, D. E. Anal. Chem. 1974, 46, 75-80.

16. Olson, K. W.; Haas, W. J. Jr.; Fassel, V. A. Anal. Chem. 1977, $49,632-637$.
17. Bear, B. R.; Fassel, V. A. Spectrochim. Acta B 1986, 41, $1089-1113$.

18. Olivares, J. A.; Houk, R. S. Anal. Chem. 1985, 57, $2674-2679$.

19. Douglas, D. J.; French, J. B. I. Anal. Atom. Spectrom. 1988, 3, 743-747.

20. Tien, P. K. I. Appl. Phys. 1954, 25, 1281-1288.

21. Kurz, E. A. Am. Lab. March 1979, 11, 67-82.

22. Olivares, J. A.; Houk, R. S. Appl. Spectrosc. 1985, 39, $1070-1077$.

23. Fulfurd, J. E.; Douglas, D. J. Appl. Spectrosc. 1986, 40, 971-974.

24. Chambers, D. M.; Hieftje, G. M. Spectrochim. Acta B 1991, 46, 761-784.

25. Dahl, D. A.; Delmore, J. F. PC./PS2 SIMION Version 4.0; Idaho Nuclear Engineering Laboratory, E. G. \& G Idaho: Idaho Falls, ID, 1990.

26. Gillson, G. R.; Douglas, D. J.; Fulford, J. E.; Halligan, K. W.; Tanner, S. D. Anal. Chem. 1988, 60, 1472-1474.

27. Tanner, S. D. Spectrochim. Acta B 1992, 47, 809-823.

28. Gray, A. L. J. Anal. Atom. Spectrom. 1989, 4, 371-373.

29. Tarr, M. A.; Zhu, G.; Browner, R. Г. Appl. Spectrose. 1991, 45, 1424-1432.

30. Bradshaw, N.; Sanderson, N. E. High Resolution Plasma Mass Spectrometer, International Patent Appl. No. PCT/GB89/ $00622,1989$.

31. Vaughan, M. A.; Horlick, G.; Spectrochim. Acta B 1990, 45, $1301-1312$.

32. Crain, I. S.; Smith, F. G.; Houk, R. S. Spectrochim. Acta B 1990 , 45, 249-259.

33. Rowan, J. T.; Houk, R. S. Appl. Spectrosc. 1989, 43, 976-980.

34. Turner, P. J. Fourth Surrey Conf. on Plasma Source Mass Spectrometry, Guildford. UK, July 1991. 